\title{
Compensation of Harmonics of Fully Controlled Loads by Using SAHF
}

\author{
Smt. SmitaSinghai ${ }^{1}$, Prof. Avinash Pandey ${ }^{2}$, Prof. Umesh Yadav ${ }^{3}$, \\ Prof. Versha Singh ${ }^{4}$, Prof. S. Gupta ${ }^{5}$ \\ Department of Electrical Engineering, National Institute of Technology, Raipur (C.G.)(INDIA)
}

\begin{abstract}
In this paper, Three Phase Shunt Active Harmonic Filter is used for harmonic compensation of fully Controlled loads by using new thyristorized Pulse Generator Circuits which generates 12 Pulses for two NonLinear three phase Loads. The three phase Non-Linear Loads are connected at the secondary of three phase Transformers with Three Phase Breakers having Transition time 5/60seconds. A new Pulse Generator topology is used for generating pulses for each of three phase non-linear loads. The Circuit used for Compensation of Harmonics having three phase IGBT based Inverter. The IGBT base d Shunt Active Harmonic Filter gets firing Pulses from PLL phase Locked Loop\& Hysteresis Switching HS. The used PLL extracts the Fundamental component of load current which is then multiplied with same RMS gain for generating the Reference current for Hysteresis Current Controller. The used Hysteresis Current Controller compares the reference current with measured current of Shunt Active Harmonic Filter for generating the pulse for three phase IGBT Inverter.
\end{abstract}

Keywords: Shunt Active harmonic filter (SAHF), IGBT inverter, Phase locked loop (PLL), Hysteresis Switching (HS), Point of common coupling (PCC), Thyristorized pulse generator.

\section{Introduction}

All Computer \& electronics loads, the use of electronic ballasts for fluorescent lighting and the extensive use of power semiconductor switches, such as in solid-state drives, all have greatly increased the nonlinear loads on power system. . However, with the large increase in the number of nonlinear loads in recent years, the distribution network response may not be so straightforward. That is, it is no longer possible to predict the network response with the same level as we obtain previously. For example, voltage reduction reduces power consumption; but at the same time, it may cause significant increases in feeder and transformer currents. All Non-linear load causes generation of Harmonics current. When Harmonic current flows to system impedance, it causes generation of Harmonic Voltages. These harmonic interferences causes overheating of motor , transformers, derating of electrical wires and electronics Devices, Abnormal operation of protective Devices like Breakers, Relay, fuses, control units, decreased motor performances Furthermore, some electronic loads with regulated output voltages, such as active power factor-corrected rectifiers, exhibit constant power demand against voltage variation. All these undesirable effects result in reducing system stability. Harmonic interferences can be minimized by installing harmonic filters. There are passive and active harmonic filters [1] [3]. Passive harmonic filters have a pre-determined frequency bandwidth and are capable of minimizing fixed orders of harmonics only. Active harmonic filters are more sophisticated and can inject anti-phase harmonic currents to the systems for harmonic compensation. They are therefore suitable for dynamic harmonic conditions where harmonic contents are varying. One kind of Active Filter is Shunt Active filter which is used for harmonic current compensation \& Reactive power Compensation [4]. It's another kind is Series Active Harmonic filter that is used for suppressing the voltage Harmonics, Voltage flicker \& decreasing the voltage Regulation [6]. The combination of these two is known as unified Power Quality Conditioner UPQC that is used for suppressing all Power Quality Problems [5][7-11].

In our Paper, we suggests Thyristorized pulse generator based Phase Locked Loop Controlled three phase IGBT Inverter used for eliminating all Power Quality problems generated by fully Controlled Non-linear loads [12-14]. The gate signal for IGBT is generated by Hysteresis Switching HS. The Hysteresis Switching has good Property of Unconditioned Stability, high Speed response \& good Accuracy [15][16]. The suggested SAHF is investigated for Compensating all power Quality issues for Thyristorized Pulse Generator based fully Controlled Non-Linear loads.

\section{Proposed Methodology}

Our methodology uses Thyristorized Pulse Generator Controlled; Phase Locked Loop \& Hysteresis Switching based IGBT Inverter used for removing all Power Quality Issues generated by fully Controlled NonLinear Loads. For eliminating all Power Quality Problems generated by Thyristorized Controlled Non-Linear loads, used PLL \& HS controlled IGBT based Inverter is connected at the Point of Common Coupling PCC. 


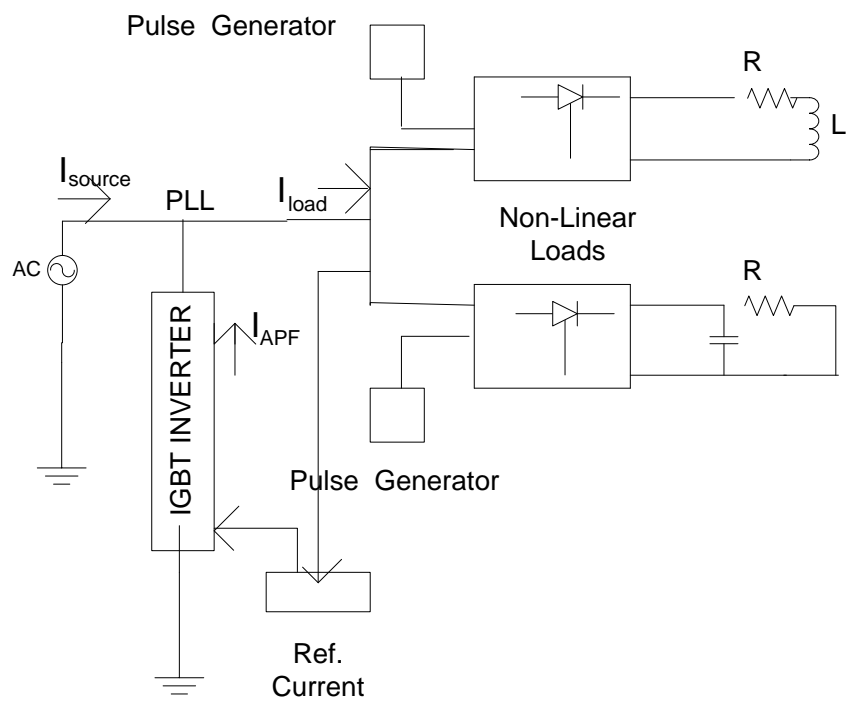

Figure1.Proposed Active Power Filter Configuration

Proposed Methodology uses Non-linear loads in which both are in Controlled mode getting triggering Pulse from Thyristorized Pulse Generator Circuit which generates 12 Pulses, having Pulse width of $60^{\circ}$. First 6 Pulses are given to first Controlled Rectifier \& Second 6 Pulses are generated for another Controlled Rectifier. Both Controlled Rectifiers are connected to the Delta Connected secondary of two Three Phase Transformer which are connected to each other by a three Phase Breaker initially Closed having a Transition time 5/60 second. Proposed Active Harmonic Filter uses PLL for extracting the fundamental component of load current which is then multiplied with the same RMS gain of load current for generating the reference current for Hysteresis Current Controller. Hysteresis Current Controller compares the reference current generated by PLL to the measured value of Active Harmonic filter current for generating the Gate trigger Pulse for three Phase IGBT Inverter.

\section{Thyristorized 12-Pulse Generator, Phase Locked Loop (PLL) \& Hysteresis Switching (HS)}

\section{A) Thyristorized 12-Pulse Generator:}

The Block used for given Pulse Generator is-

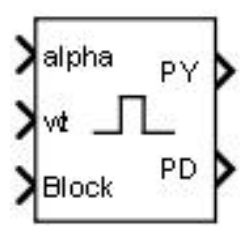

Figure2. Thyristorized 12-Pulse Generator

The Pulse Generator Block generates two pulse trains. Thyristorized Pulse Generator Circuit which generates 12 Pulses, having Pulse width of $60^{\circ}$. First 6, PY Pulses are given to first three phase Controlled Rectifier \& Second 6, PD Pulses are generated for another three Phase Controlled Rectifier. The ordering of pulses in the pulse trains corresponds to the natural order of commutation of a three-phase controlled converter, as shown in the following figure. 


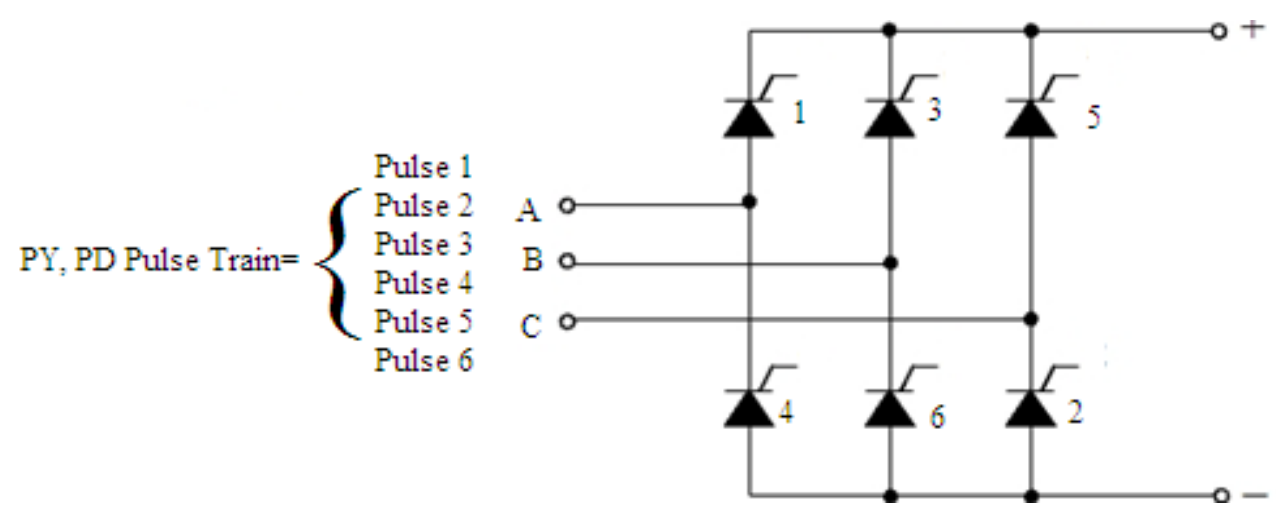

Figure 3.Sequence of Pulses Generated by Thyristorized Converter for 3-Phase Controlled Converter

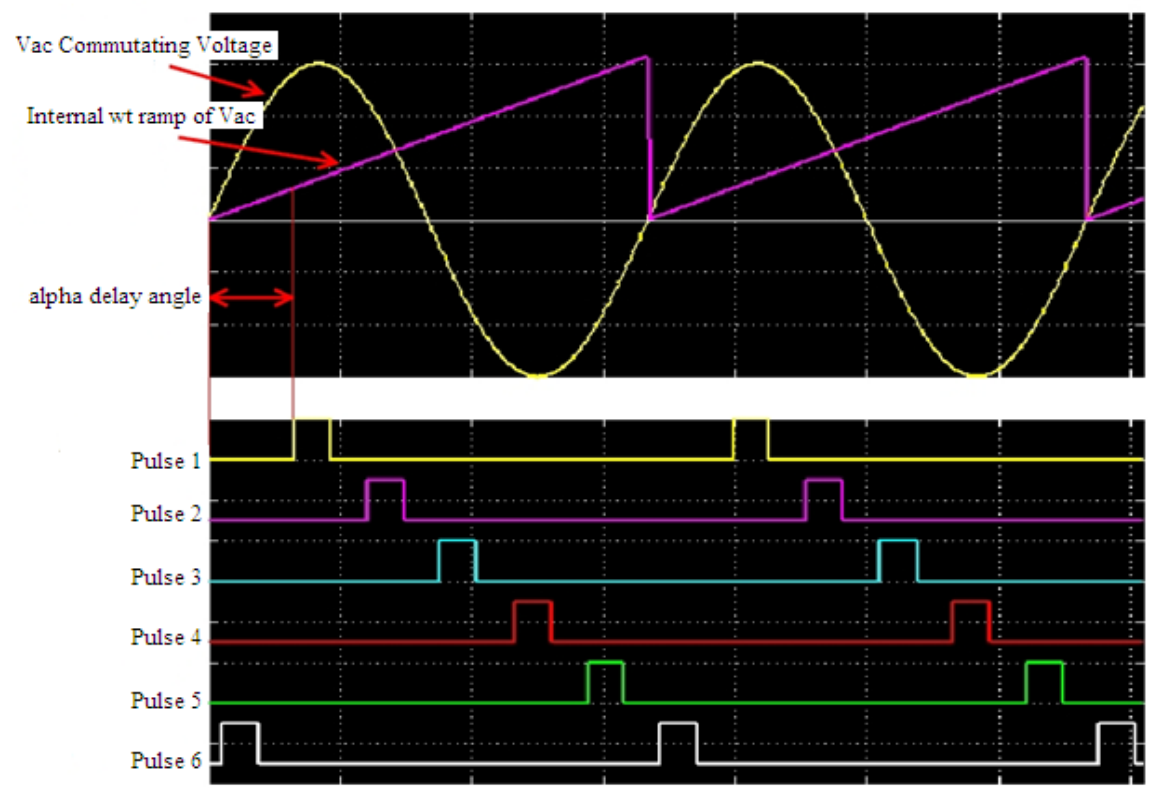

Figure 4. Waveform of Pulses Generated by Thyristorized Converter for 3-Phase Controlled Converter

There are the three inputs of Thyristorized Pulse Generator. Firing angle 'alpha' is the reference signal, 'wt signal' is an angle varying between 0 and $2 *$ pi radians, synchronized on zero crossings of the fundamental (positive-sequence) of phase A of the primary voltage of the converter transformer. The wt signal is normally obtained from a phase locked loop (PLL) system. The Thyristorized Pulse Generator block generates internal wt ramps to control the pulses. The delay angle 'alpha' is expressed in electrical degrees by which the pulse is delayed relative to angle zero of its commutating voltage. This input can be connected to a Constant block, or it can be connected to a controller system to control the pulses of the generator. The Thyristorized Pulse Generator block can be configured to work in double-pulsing mode. In this mode two pulses are sent to each thyristor of three phase Controlled rectifier, a first pulse is to be sent when alpha angle is reached, and then a second pulse 60 degrees later, when the next thyristor is fired.

\section{B) PLL Introduction:}

Today various methods of synchronizing techniques are available. One is open loop techniques that that directly estimates the phase angle of the input voltage and input current signals. Second one is closedloop methods in which the estimation of the phase is adaptively updated through a loop mechanism having self locking tendency. It means PLL is a negative feedback control system in which output frequency fout tracks with the input frequency fin

And rising edge of output clock make a alignment with the rising edge of input clock.

(i)PLL for trigger pulse Generation:

In Proposed methodology, one phase locked loop system is used for generating triggering Pulse for Thyristorized Pulse Converter. 


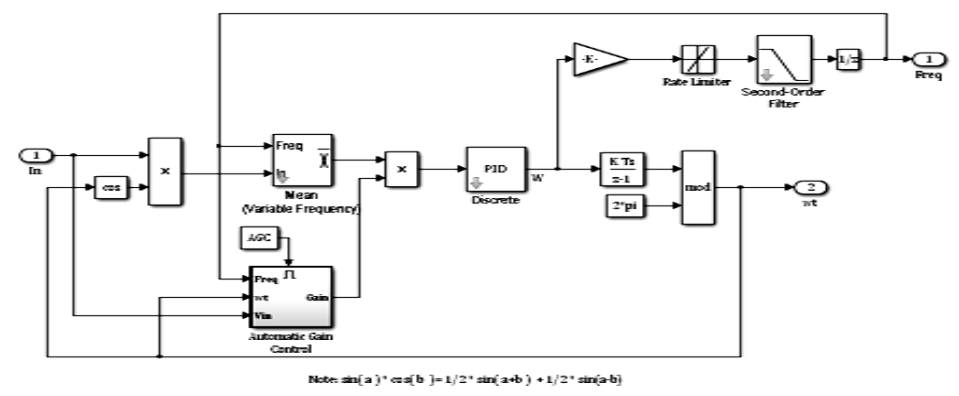

Figure 5. PLL used for Thyristorized pulse Converter

This Phase Locked loop PLL is used to synchronize on a variable frequency sinusoidal signal when automatic gain control is enabled, the input phase error of the PLL regulator is Scaled according to input signal magnitude. Input Signal 1 of this PLL is normalized supply input signal in per unit pu. There are the two outputs of this PLL. One of the output of this PLL is measured in frequency Hz where measured frequency is equal to $\omega /(2 *$ pi). Another output of this PLL is Ramp wt varying between 0 \& (2*pi) synchronizing on zero crossing (rising) of fundamental input signal.

\section{(ii)PLL for reference current Generation}

Normally, low power factor LPF or phase locked loop PLL blocks are used for determining unit reference signal generation. But they have some drawbacks with them, such as low power factor LPF produces phase delay in the system and fine tuning is required in terms of gain and phase margins. Also, under distorted supply voltage conditions selection of cut off frequency plays a major role. Therefore, A phase Locked Loop PLL block can be used instead of LPF for generating unit reference signal. In Proposed methodology, the three phase load currents $I_{a b c l o a d}$ are first converted into unit magnitude signal by multiplying it with same RMS gain, Multiplication results compares with the actual value of load current, Subtraction results acts as a reference current for hysteresis current controller. Hysteresis Current Controller compares the reference current generated by PLL to the measured current generated by IGBT Inverter for Pulse generation for IGBT inverter. In this way, the reference fundamental unit templates will be multiplied by error signal generated by IGBT based voltage controller to generate final sinusoidal reference current signal also in phase with source voltage to make power factor unity. Here $\mathrm{I}_{\mathrm{ABCF}}$ is the fundamental component of current generated by PLL \& HS based IGBT Inverter. The block diagram of proposed controller is shown in Fig. 6.

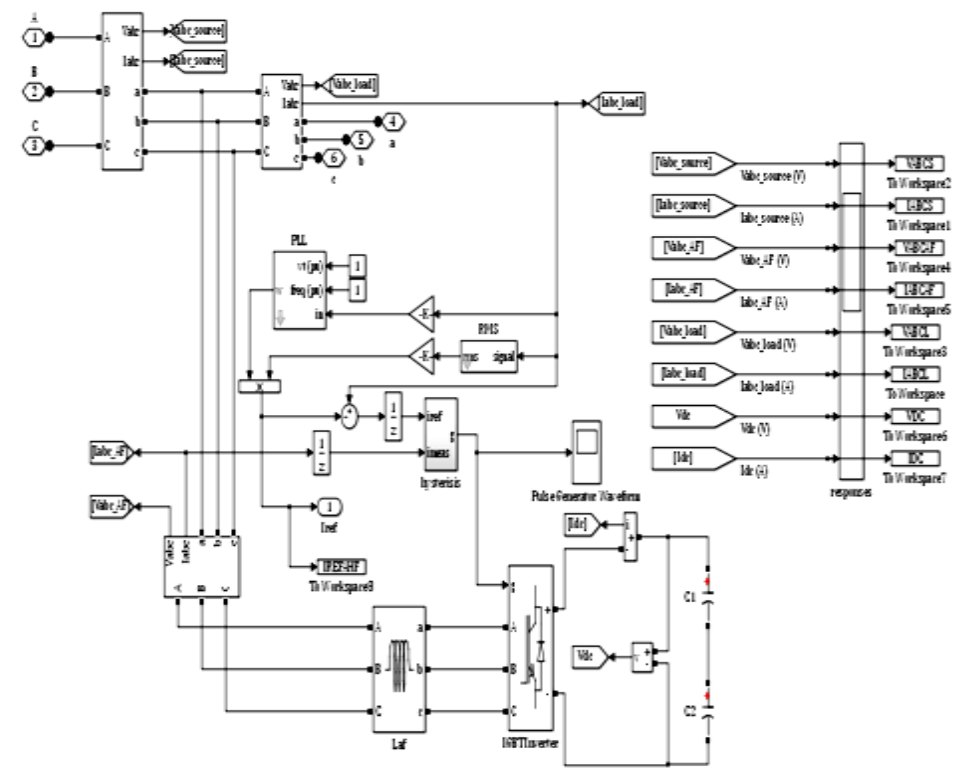

Figure6. PLL \& Hysteresis Switching used for Shunt Active Harmonic Filter used for Harmonic Elimination of Non-Linear Loads 


\section{C) Introduction to Hysteresis Switching:}

To obtain high accuracy and to compensate for the voltage disturbances, a high loop gain within the safe stability margin must be adopted. Both of two very difficult to achieve. The performance can also be improved by increasing the switching frequency. However, as in active power filters, the power involved is quite high and the available switching components do not allow too high frequencies. Moreover, as the switching frequency increases, the effects of the dead times increase as well, which add to the voltages disturbances mentioned above. A satisfactory solution for these requirements has given by the hysteresis current-control technique, which is characterized by unconditioned stability, good accuracy \& fast response. In our topology, the hysteresis band is used to control the shunt line current as per reference current generated by PLL \& HS to determine the switching gate signals for IGBT inverter. When the shunt line current exceeds the upper band, the comparators generate control signals in such a way to decrease the current and keep it between the bands. The controlled compensation current is injected such that the shunt line current follows the reference current. Hence the shunt line current becomes close to reference currents estimated by proposed Phase Locked Loop PLL \& Hysteresis Switching HS.
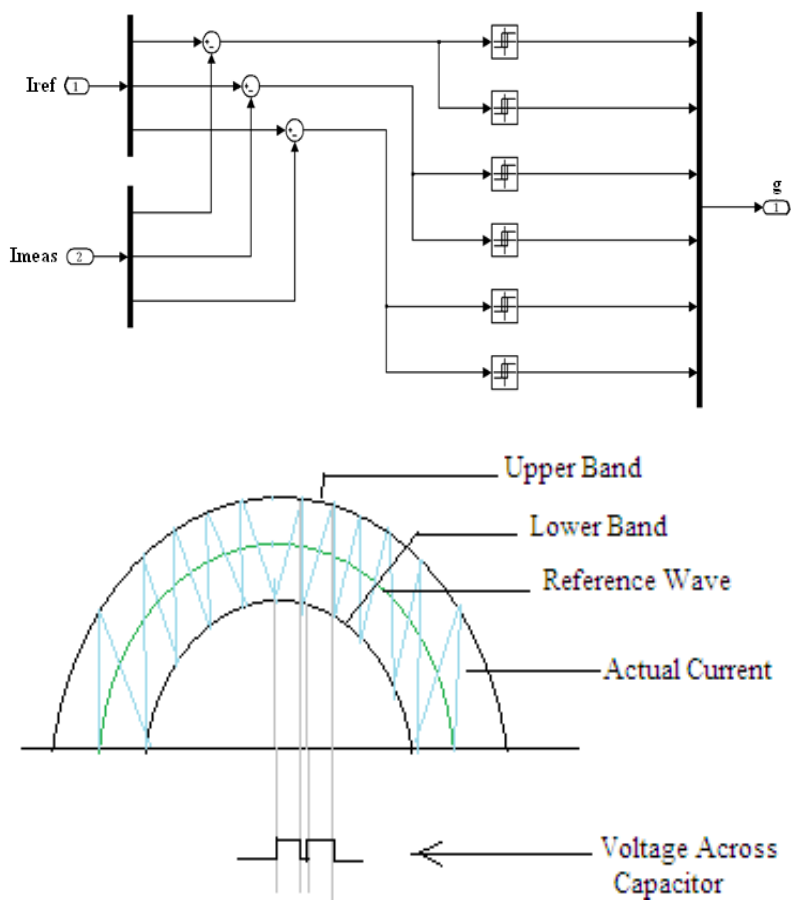

Upper hysteresis band limit $=$ iref $+\Delta(1+\varepsilon)$, Lower hysteresis band limit $=$ iref $-\Delta(1+\varepsilon)$

Figure7. Proposed Hysteresis Band Current Controller

Within the Hysteresis band, If the measured value of shunt line current exceeds the maximum current limit of the hysteresis band, the upper half switch of the inverter arm is turned off and the lower half switch is turned on. The result of that is, the current starts to decay. Within the hysteresis band if the measured value of current crosses the minimum current limit of the hysteresis band, the lower switch of the inverter arm is turned off and the upper switch is turned on. The result is that, the measured value of current gets back into the hysteresis band. In this way measured value of shunt line current is forced to track the reference current within the hysteresis band. Hence by using PLL \& HS from sampled load current and load voltage, the corresponding fundamental real components of the voltage and current are extracted.

Where

$$
\begin{aligned}
& I_{f}=I_{l}-k K_{0} E_{m} \sin (w t)-k K_{1} E_{m} \sin (w t) \\
& V s=V_{l}-k K_{0} E_{m} \sin (w t)-k K_{1} E_{m} \sin (w t)
\end{aligned}
$$

$$
\begin{aligned}
& K_{1}=\left(\frac{1}{w}\right) R C I E_{m} \sin (w t) \\
& I_{L}=I_{P}+I_{Q}+I_{H} \\
& V_{L}=V_{P}+V_{Q}+V_{H}
\end{aligned}
$$




$$
\begin{gathered}
I_{f}=I_{l}-k K_{0} E_{m} \sin (w t) \\
I_{f}=I_{P}+I_{Q}+I_{H}-k K_{0} E_{m} \sin (w t) \\
I_{f}=I_{Q}+I_{H} \\
I_{P}=k K_{0} E_{m} \sin (w t)
\end{gathered}
$$

Where

IL- fundamental Component of load Current

IP- fundamental Active Component of Load Current/Load Voltage

$I_{Q}-$ fundamental Reactive Component of Load Current/Load Voltage

K1-Proportional Coefficient

KO-DC component of Integrator Output

\section{Simulation Results}

Simulation Model is carried out on a Matlab /Simulink software R2013a. Figure 8 represents the simulation model of harmonic compensation of fully controlled loads with SAHF. Figure 9 represents the Simulink model of fully controlled loads without SAHF. Harmonics which are generated by non-linear loads is removed by Thyristorized Controlled PLL based Shunt Active Power Filter. Given model considers the harmonics due to non-linear (fully controlled) loads and the disturbance presents in supply system also taken into consideration. Figure 9.1 represents the input current wave shape is non-sinusoidal which represents unbalanced supply. For Proposed model, the Simulation time is 0.08 seconds. Figure 9.2 shows the 3 phase injected current waveform by ASHF at the point of common coupling. Figure 9.3 shows 3-phase load current waveform which is a combination of two three phase Controlled (delta-delta) loads. Table 1 shows simulation parameters.

\section{FFT Analysis}

The Fast Fourier Transform (FFT) Analysis is used to measures the order of harmonics with the fundamental frequency at $50 \mathrm{~Hz}$ of the source current and also considers THD (total harmonic distortion) presents in selected signal. In our model measurement block is used for finding error in between Source \& load current waveform. The FFT analysis of given Model for selected signal with and without the use of Shunt Active Filter is shown in Figure 9.4(i) \& 9.4(ii). The figure 8 represents the Simulink Model of Harmonic Compensation of fully Controlled Loads with SAHF. And the figure 9 shows Simulink Model of the Nonlinear loads directly connected with supply system that means without the use of Active Filter. Without the use of Active filter, total harmonic Distortion THD is about $20.94 \%$ which is greatly reduced upto about $0.40 \%$ with the use of Thyristorized Controlled Shunt Active Harmonic Filter. Figure 9.4(i) shows the FFT waveform for selected signal with the use of SAHF. And figure 9.4(ii) shows the FFT waveform for same signal without the use of SAHF.

\section{Conclusion}

This methodology proposes an implementation of a 12-Pulse thyristorized Controlled three-phase shunt active harmonic filter with phase locked loop PLL \& Hysteresis Controlled HS, having a combination of two fully Controlled loads. Simulation result shows, this system provides unity power factor operation of non-linear loads with adding that reduces the harmonics from $20.94 \%$ to $0.40 \%$. 
Table I System Parameters

\begin{tabular}{|c|c|c|c|}
\hline \multirow{4}{*}{$\begin{array}{l}\text { SYSTEM } \\
\text { SOURCE }\end{array}$} & \multicolumn{2}{|l|}{ PARAMETERS } & \multirow{2}{*}{$\begin{array}{l}\text { VALUE } \\
4160 * \sqrt{3} * \sqrt{2} \mathrm{~V} \\
\end{array}$} \\
\hline & VOLTAGE & Vs & \\
\hline & FREQUENCY & $\mathrm{f}$ & $50 \mathrm{~Hz}$ \\
\hline & INDUCTANCE & Ls & $1 \times 10^{-5} \mathrm{H}$ \\
\hline \multirow[t]{3}{*}{ LOAD 1} & \multirow{3}{*}{$\begin{array}{l}\text { CONTROLLED } \\
\text { RECTIFIER } \\
\text { (DELTA-DELTA) }\end{array}$} & $\begin{array}{l}\text { THYRISTOR ON- } \\
\text { RESISTANCE }\end{array}$ & $1 \mathrm{X} 10-{ }^{3} \mathrm{OHMS}$ \\
\hline & & $\begin{array}{l}\text { SNUBBER } \\
\text { RESISTANCE }\end{array}$ & $1 \mathrm{X} 10^{3} \mathrm{OHMS}$ \\
\hline & & $\begin{array}{l}\text { SNUBBER } \\
\text { CAPACITANCE }\end{array}$ & $1 \mathrm{X} 10-{ }^{6} \mathrm{~F}$ \\
\hline \multirow[t]{3}{*}{ LOAD 2} & \multirow{3}{*}{$\begin{array}{l}\text { CONTROLLED } \\
\text { RECTIFIER } \\
\text { (DELTA-DELTA) }\end{array}$} & $\begin{array}{l}\text { THYRISTOR ON- } \\
\text { RESISTANCE }\end{array}$ & $1 \mathrm{X} 10-{ }^{3} \mathrm{OHMS}$ \\
\hline & & $\begin{array}{l}\text { SNUBBER } \\
\text { RESISTANCE }\end{array}$ & $1 \mathrm{X} 10^{3} \mathrm{OHMS}$ \\
\hline & & $\begin{array}{l}\text { SNUBBER } \\
\text { CAPACITANCE }\end{array}$ & $1 \mathrm{X} 10-^{6} \mathrm{~F}$ \\
\hline \multirow[t]{5}{*}{ SAHF } & \multirow{5}{*}{$\begin{array}{l}\text { SHUNT ACTIVE } \\
\text { HARMONIC } \\
\text { FILTER }\end{array}$} & LAF & $1 \mathrm{X} 10^{-3} \mathrm{OHMS}$ \\
\hline & & MAX.CURRENT & $4000 \mathrm{~A}$ \\
\hline & & FREQUENCY & $50 \mathrm{HZ}$ \\
\hline & & $\begin{array}{l}\text { DC BUS } \\
\text { CAPACITANCE }\end{array}$ & $\begin{array}{l}5 \times 10^{-4} \\
\mathrm{~F}\end{array}$ \\
\hline & & VOLTAGE & $440 \mathrm{~V}$ \\
\hline \multirow{2}{*}{$\begin{array}{l}\text { THYRISTORIZED 12- PULSE } \\
\text { GENERATOR }\end{array}$} & \multirow{2}{*}{$\begin{array}{l}\text { SINGLE PULSING } \\
\text { MODE }\end{array}$} & FREQUENCY & $50 \mathrm{~Hz}$ \\
\hline & & PULSE WIDTH & 60 degree \\
\hline THREE PHASE BREAKER & (CLOSED) & TRANSITION TIME & $5 / 60 \mathrm{Sec}$ \\
\hline \multirow{5}{*}{$\begin{array}{l}\text { THREE PHASE (TWO WINDING) } \\
\text { TRANSFORMER }\end{array}$} & \multirow[t]{5}{*}{ DELTA-DELTA } & POWER/freq & $25 \mathrm{MVA}, 50 \mathrm{~Hz}$ \\
\hline & & $\mathrm{V}_{\mathrm{RMS}}, \mathrm{R} 1(\mathrm{pu}), \mathrm{L} 1(\mathrm{pu})$ & $4160 \mathrm{~V}, 0.002,0.08$ \\
\hline & & $\mathrm{V} 2_{\mathrm{RMS}}, \mathrm{R} 2(\mathrm{pu}), \mathrm{L} 2(\mathrm{pu})$ & $4160 \mathrm{~V}, 0.002,0.08$ \\
\hline & & $\mathrm{Rm}(\mathrm{pu})$ & 500 \\
\hline & & $\mathrm{Lm}(\mathrm{pu})$ & 500 \\
\hline
\end{tabular}

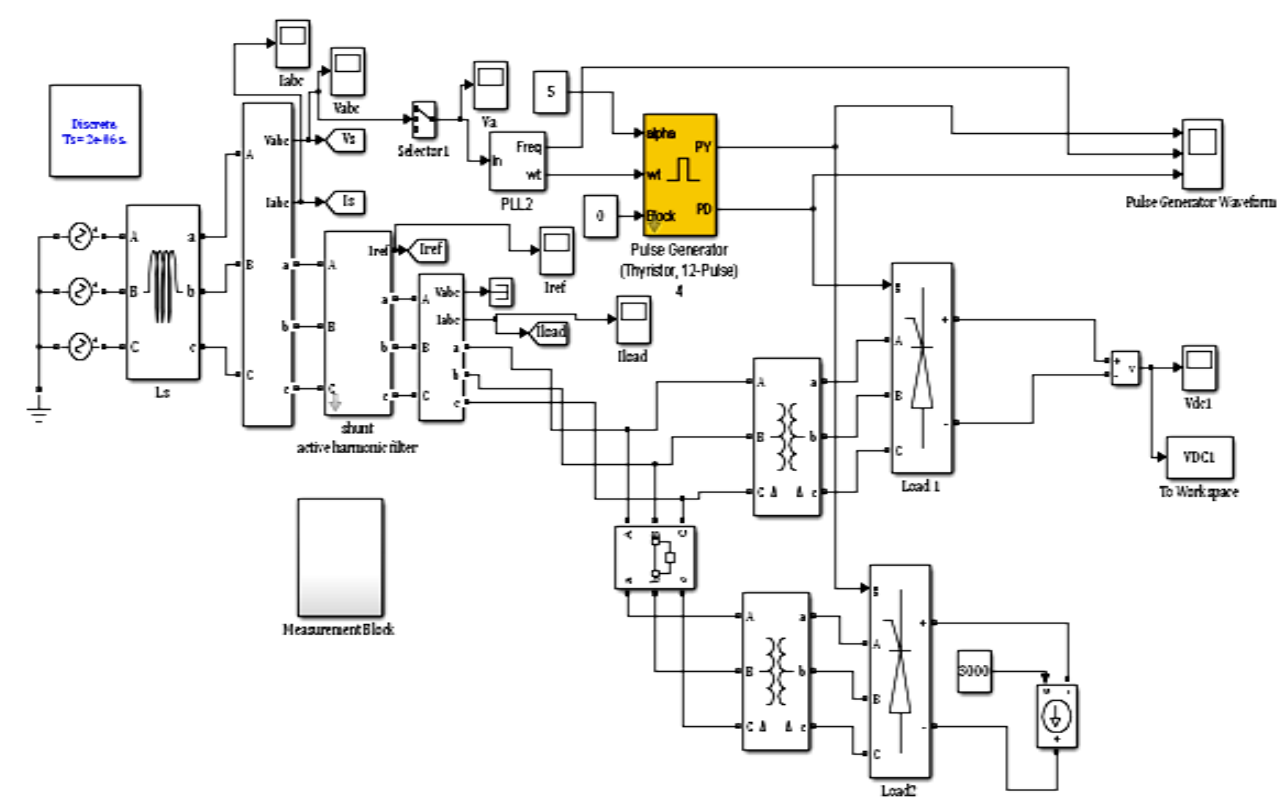

Figure 8. Simulink Model of Harmonic Compensation of fully Controlled Loads with SAHF 


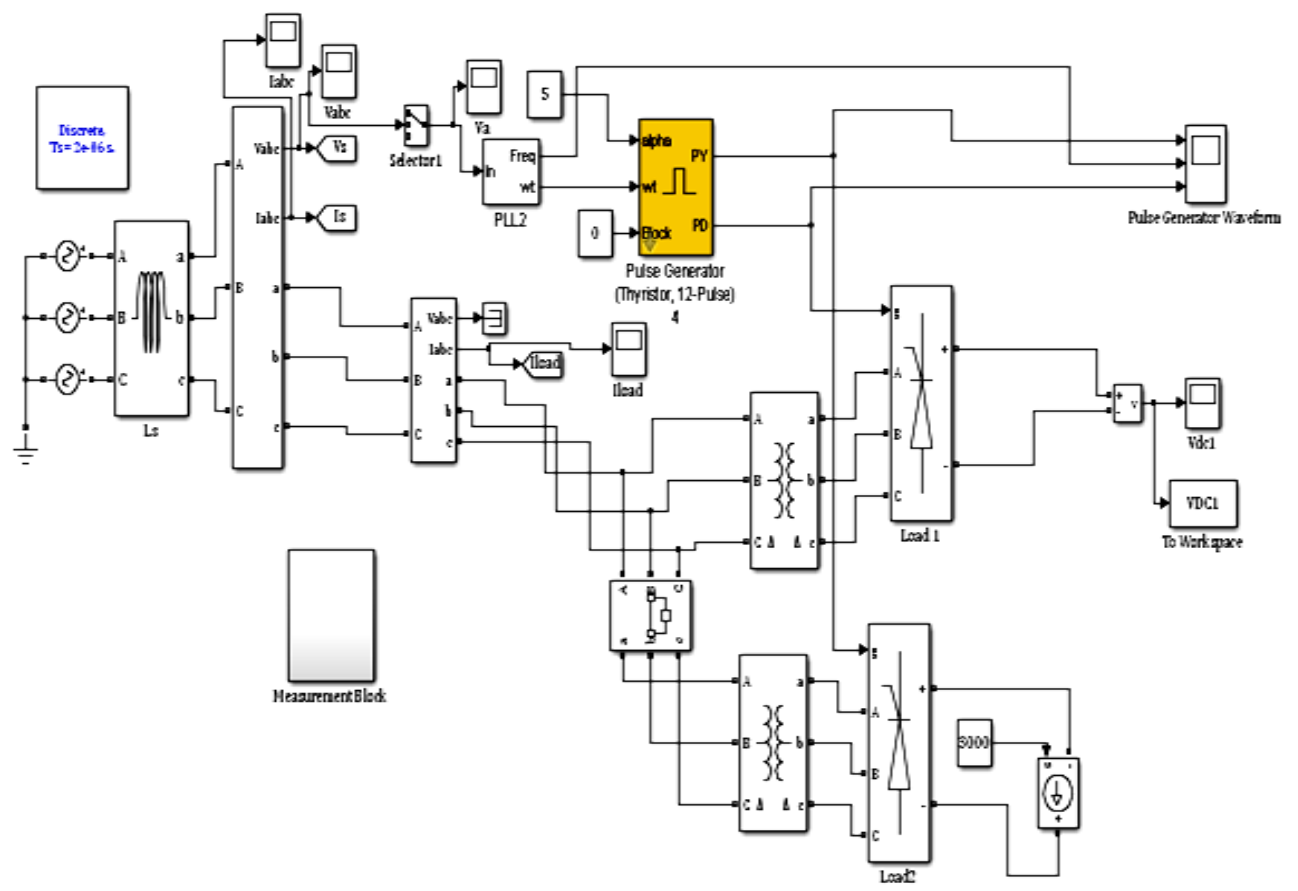

Figure 9. Simulink Model of Harmonic Compensation of fully Controlled Loads without SAHF

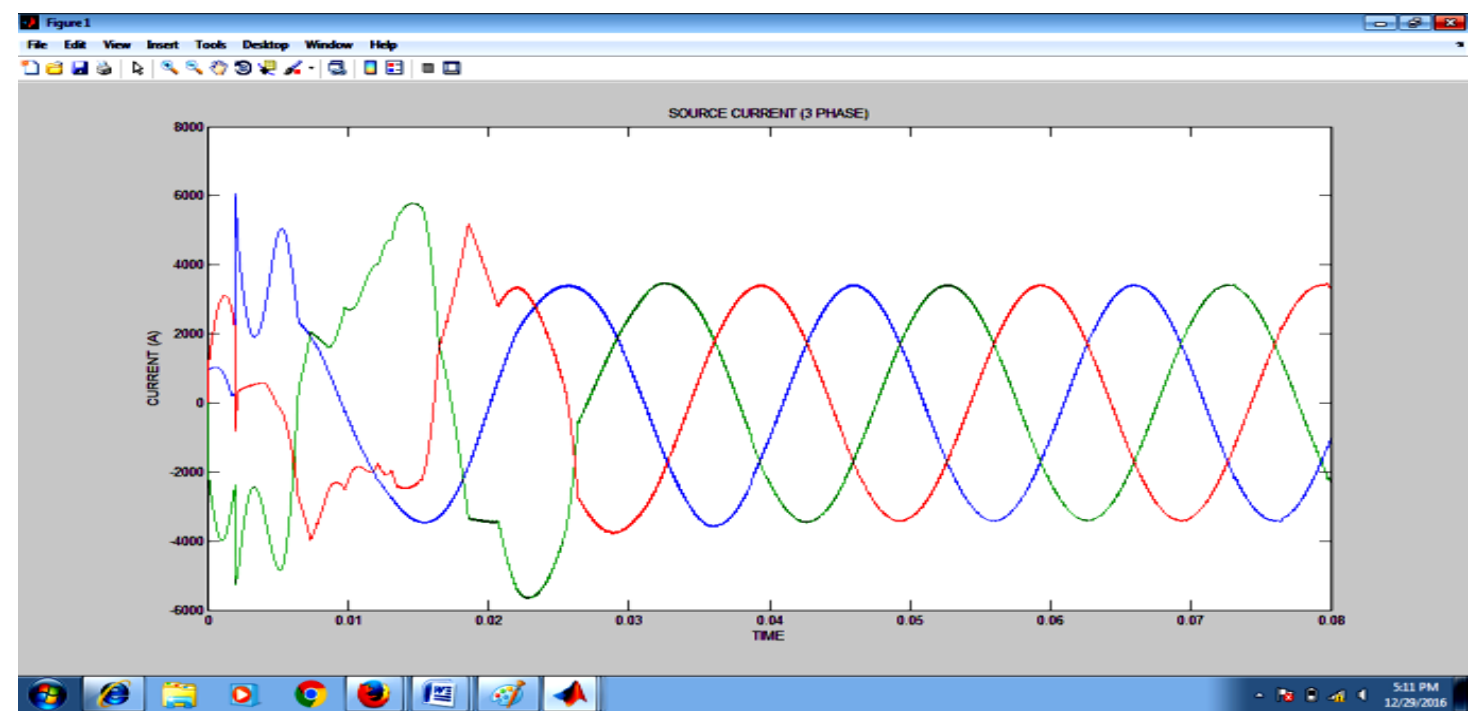

Figure 9.1 3 phase Source Current Waveform 


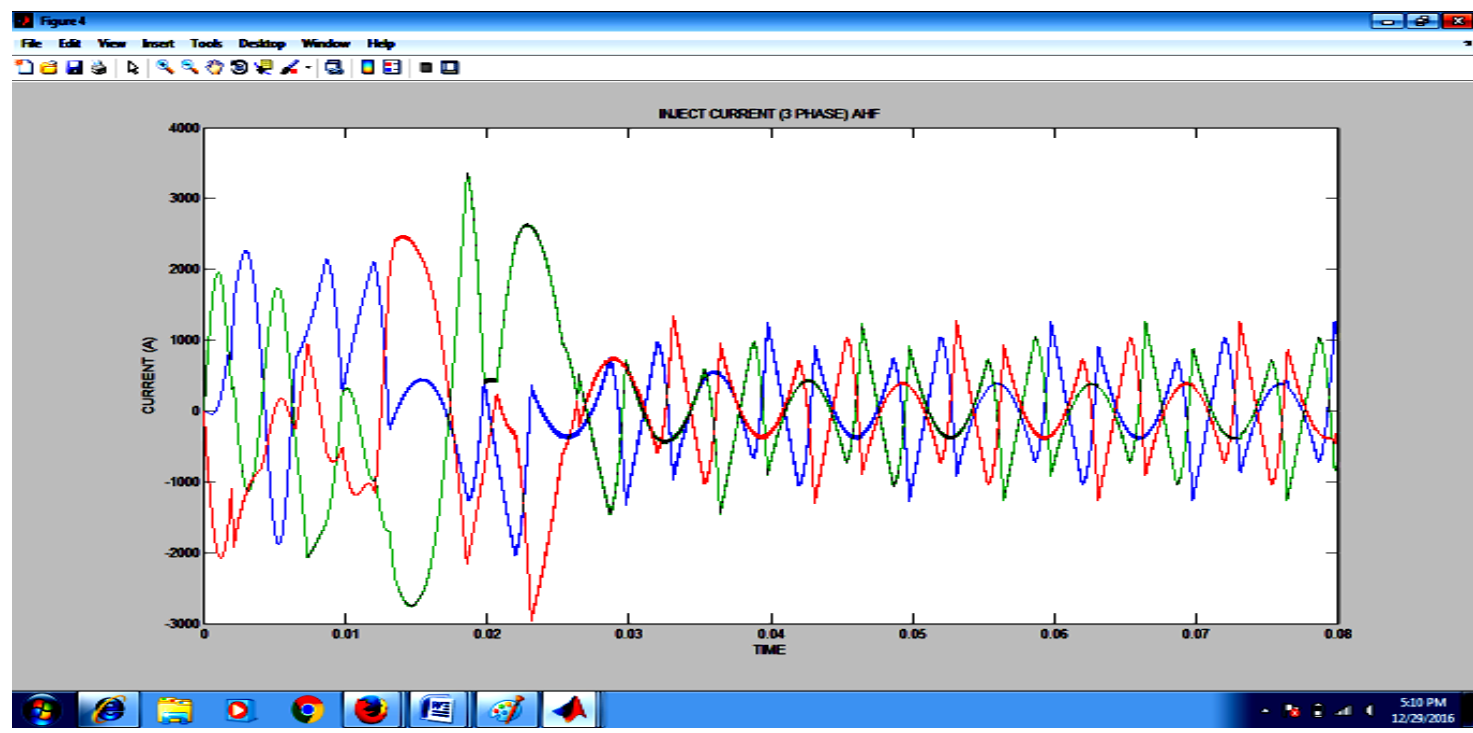

Figure 9.2 3 phase injected current waveform

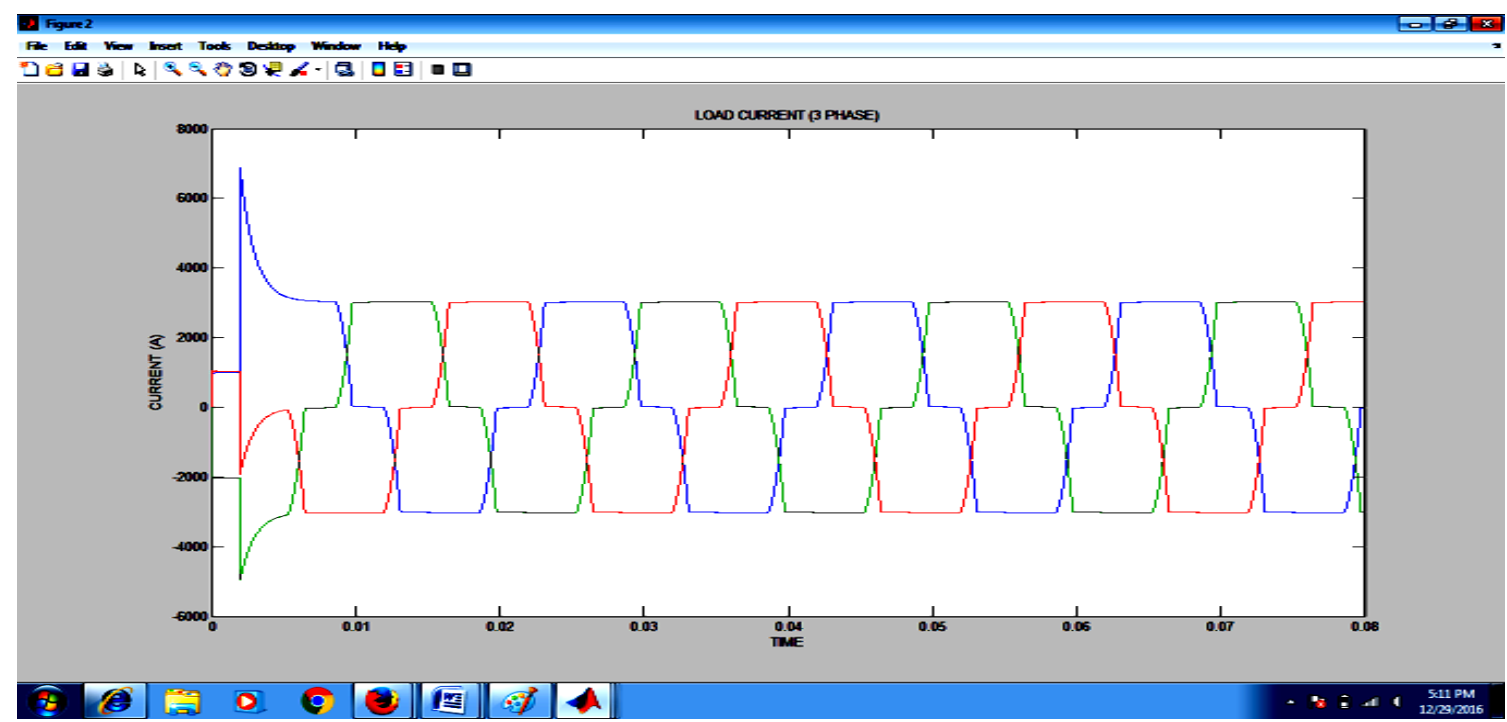

Figure 9.33 phase Load current waveform

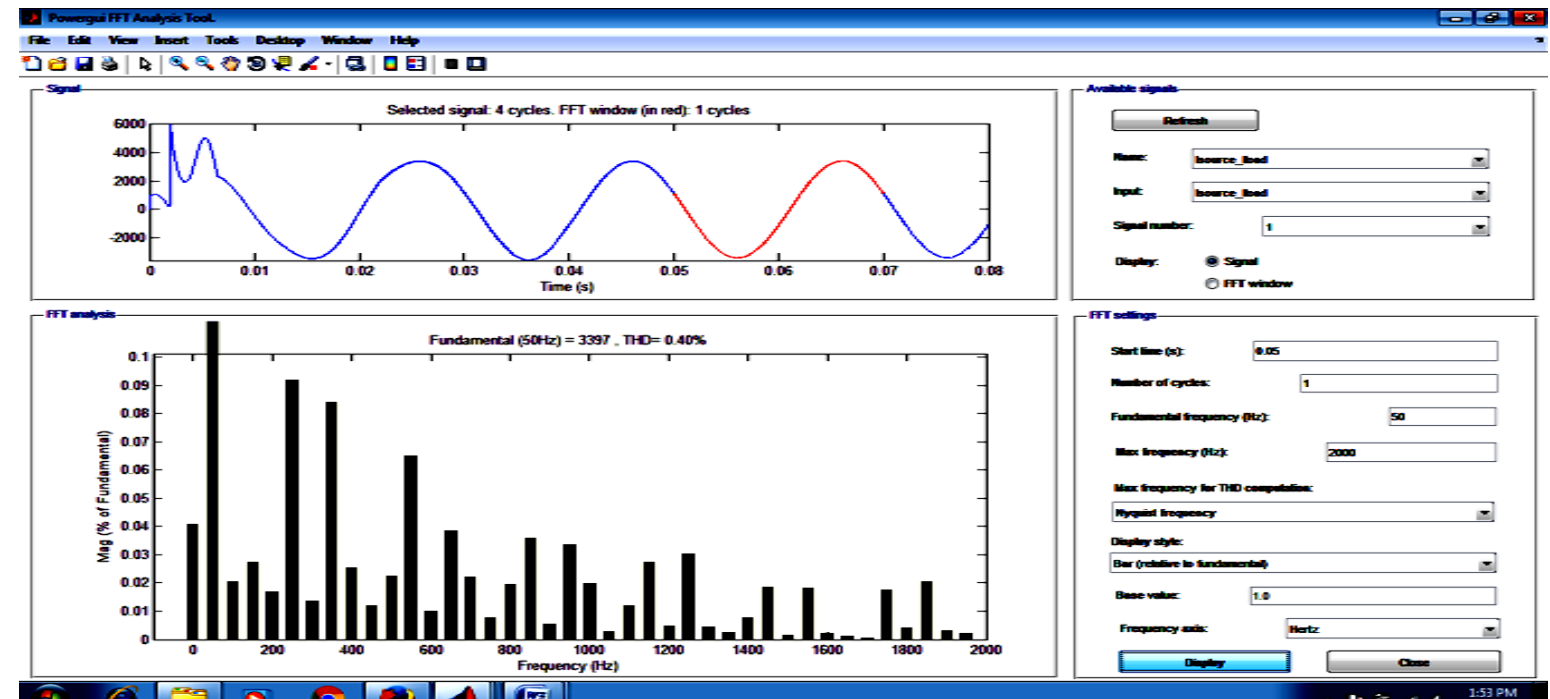

Figure 9.4(i) FFT waveform of Non-Linear loads with SAHF (THD 0.40\%) with fundamental freq $50 \mathrm{~Hz}$ 

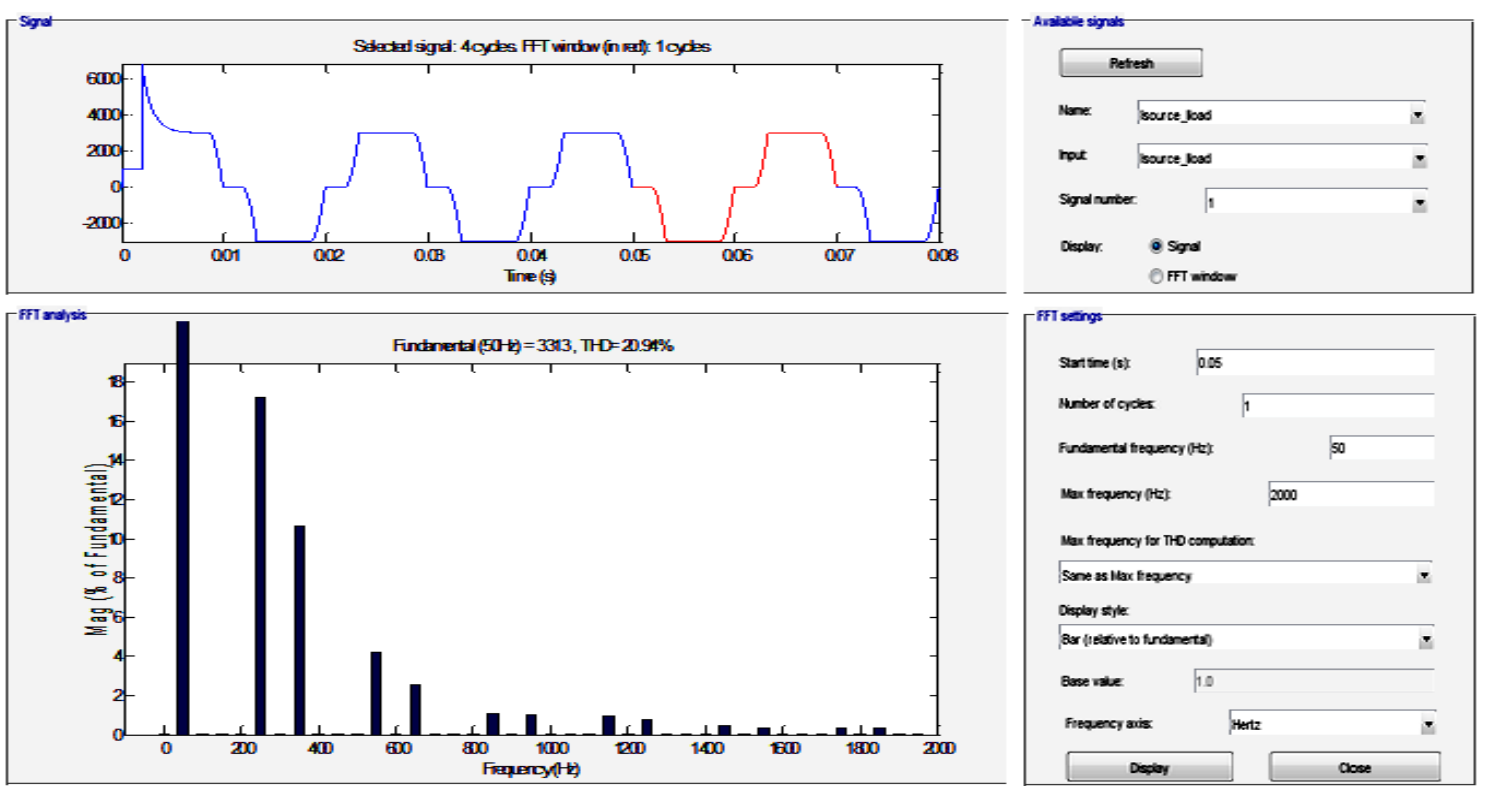

Figure9. 4(ii) FFT waveform of Non-Linear loads with SAHF (THD 20.94\%) with fundamental freq $50 \mathrm{~Hz}$

\section{References}

[1]. M. El-Habrouk, M.K. Darwish and P. Mehta, “Active Power Filter: A Review,” IEEE Proc. Electr.Power.Appl, pp. 403-413, Sept 2000

[2]. B. Singh, K. Al-Haddad and A. Chandra, “A Review of Active Filter for Power Quality Improvements,” IEEE Trans. on Industrial Electronics, pp. 960-971, Feb 1999

[3]. $\quad$ Fang Zheng Peng, "Harmonic Sources and Filtering Approaches," IEEE Industry Applications Magazine, pp. 18-25, July 2001

[4]. Fang Zheng Peng, "Application issues of Active Power Filters," IEEE Industry Applications Magazine, pp. 21-30, Sept 1998

[5]. H.L. Jou, "Performance Comparison of the Three-phase Active-power-filter Algorithms," IEE Proc. Gener. Trans. Distrib., pp. 646652, Nov 1995

[6]. Adil M. Al-Zamil and D.A Torrey, "A Passive Series, Active Shunt Filter for High Power Applications," IEEE Trans. on Power Electronics, pp. 101-109, January 2001

[7]. S. Rahmani, Ab. Hamadi, Student Member IEEE, and K. Al-Haddad, Fellow IEEE "A New Combination of Shunt Hybrid Power Filter and Thyristor Controlled Reactor for Harmonics and Reactive Power Compensation” 2009 IEEE Electrical Power \& Energy Conference.

[8]. Hirofumi Akagi, Fellow, IEEE, and Ryota Kondo, " A Transformerless Hybrid Active Filter Using a Three-Level Pulsewidth Modulation (PWM) Converter for a Medium-Voltage Motor Drive” IEEE TRANSACTIONS ON POWER ELECTRONICS, VOL. 25, NO. 6, JUNE 2010

[9]. ZHENG Jiakun, MENG Chao, LI Po, HONG Yongqiang, "The Study of Transformerless Shunt Hybrid Active Power Filter Compensation for Unbalanced Load" 2012 IEEE 7th International Power Electronics and Motion Control Conference - ECCE Asia

[10]. June 2-5, 2012, Harbin, China.

[11]. Ab. Hamadi, S. Rahmani, Member IEEE, and K. Al-Haddad, Fellow member IEEE "A Novel Hybrid Series Active Filter for Power", pp 1100-1104, 2005

[12]. R. D. Patidarl, Student Member, IEEE and S. P. Singh, "A Fast Acting 1/z Controller for Shunt Active Filter Operation for Harmonics and Reactive Power Compensation" 2008 IEEE Region 10 Colloquium and the Third International Conference on Industrial and Information Systems, Kharagpur, INDIA December 8 -10, 2008.

[13]. M.asadi, A.Jalilian, H.F.Farahani, "Compensation of unbalanced non linear load and neutral current using stationary reference frame in shunt active filters", 2010 IEEE.

[14]. JenoPaul P, Ruban Deva Prakash T, Jacob Raglend Electrical \& Electronics Engineering Nooral Islam University, Tamilnadu, "Adaptive PLL controller based shunt Active Filter for power quality improvement in Matrix converter" International Journal of Applied Engineering Reseach,DINDIGUL Vol 1,No 4, 2011.

[15]. Varsha Prasad, Dr Chirag Sharma, Department of E\&CE, Nitte Meenakshi Institute of Technology, Yelahanka, Bangalore-560 064, India "A Review of Phase Locked Loop" International Journal of Emerging Technology and Advanced Engineering, Volume 2, Issue 6, June 2012.

[16]. Mohamed R.Amer, Sherif A. Zaid, Assistant Professor in the Department of Electrical Power \& Machine, Cairo University, Egypt, Osamn A. Mahgoub Professor in the Department of Electrical Power \& Machine, Cairo University, Egypt, "New Hysteresis Control Method for Three Phase Shunt Active Power Filter" Proceeding of International Multiconference of Engineers \& Computer Scientist 2011, Hongkong 